\title{
Frequency of Chlamydia trachomatis infection in cervical intraepithelial lesions and the status of cytological p16/Ki-67 dual-staining
}

\author{
R. Robial ${ }^{1 *}$ (D, A. Longatto-Filho $2,3,4,5$, C. M. Roteli-Martins ${ }^{6}$, M. F. Silveira ${ }^{7}$ D. Stauffert ${ }^{7}$, G. G. Ribeiro ${ }^{8}$, I. M. Linhares ${ }^{1}$,
} M. Tacla ${ }^{1}$, M. A. Zonta ${ }^{9}$ and E. C. Baracat ${ }^{1}$

\begin{abstract}
Background: Chlamydia trachomatis (Ct) is not a disease subject to mandatory reporting in Brazil, and the prevalence rate of this genital infection varies according to the region in which studies are conducted, as well as by the detection technique employed. Ct has been associated with persistence of Human papillomavirus (HPV) infection and the facilitation of cervical carcinoma development. We evaluated the Chlamydia trachomatis infection and its association with cytology, p16/Ki-67 dual-stained cytology and cervical intraepithelial lesions status in a screening cohort in Brazil.

Methods: This was a cross-sectional study of 1481 cervical samples from asymptomatic women aged 18 to 64 . Samples were collected for liquid-based cytology and Ct detection by polymerase chain reaction. p16/Ki-67 double staining was performed on samples with abnormal cytology. Statistical analysis was by chi-square and likelihood-ratio tests. Odds ratio (OR) and $95 \%$ confidence intervals $(95 \% \mathrm{Cl})$ were determined.

Results: The frequency of Ct was $15.6 \%$ and its presence was not associated with detection of p16/Ki-67 [OR $=1$. $35(0.5-3.4)]$. There was also no association between abnormal cervical cytology and Ct-positivity [OR $=1.21(0.46-3.2)]$. Associations were observed between p16/Ki-67 and high-grade lesions detected by cytology and in biopsies [OR $=3.55$ (1.50-8.42) and $\mathrm{OR}=19.00(0.6-7.2)$, respectively].

Conclusions: The asymptomatic women in our study had a high frequency of $\mathrm{Ct}$ infection but this was not associated with p16/Ki-67 detection in samples with abnormal cytology. The expression of p16/Ki-67 was highest in women with high-grade CIN $(p=0.003)$.
\end{abstract}

Keywords: Chlamydia, Cervical cancer, Immunocytochemistry, ki 67

\section{Background}

Chlamydia trachomatis $(\mathrm{Ct})$ is not a disease subject to mandatory reporting in Brazil, and the prevalence rate of this genital infection varies according to the region in which studies are conducted, as well as by the detection technique employed [1-4]. Ct has been associated with persistence of Human papillomavirus (HPV) infection

\footnotetext{
* Correspondence: renata.robial@hc.fm.usp.br

${ }^{1}$ Division of Gynecologic Clinic, Faculdade de Medicina da Universidade de São Paulo, São Paulo, Brazil

Full list of author information is available at the end of the article
}

and the facilitation of cervical carcinoma development. It has also been hypothesized that Ct may promote HPV access and entry in to the basal layer of the epithelium by inducing chronic inflammation, cervical hypertrophy and metaplasia. Metaplasia is a preferred HPV target [5]. and these biological effects increase the risk of cervical cell transformation and the persistence of infection by oncogenic HPV types. A concomitant Ct and HPV infection is hypothesized to increase the expression of Ki-67 (a marker for proliferation of the cervical epithelium) by HPV-generated mitogenic actions and by the antiapoptotic activity elicited by both infectious agents [5] 
Ct may also increase protein expression of oncogenic HPV16 in low-grade lesions [5].

Cervical cancer screening via cytology may reduce mortality by up to $50 \%$ under appropriate conditions and when solid population coverage is implemented; however, the sensitivity of cytology to detect CIN or invasive cancer may be $<60 \%$ [6].

An increased understanding of how HPV contributes to cervical cell neoplastic transformation led to the routine use of biomarkers, such as p16, to identify HPVmediated transformation. Studies have suggested that analysis for the p16 biomarker by cytology and histology in cervical lesions may have clinical utility by optimizing the efficiency of cytological tests [7]. Such findings have ensured greater efficiency in the early detection of cervical cancer. However, since some normal cervical cells may express p16, it is necessary to conduct additional morphologic evaluations. A recently developed p16 and Ki-67 detection kit enables the recognition of abnormal cells based on the double staining of both markers in the same cell, thereby possibly reducing the need for morphologic interpretation [7].

Recent publications claims that p16/Ki-67 detect oncogenic molecular changes induced by a persistent HPV infection in the cell through detection of concordant expression of the tumors suppressor protein p16 (also cyclin-dependent kinase inhibitor 2A) and the proliferation marker Ki-67 in the same cell, which are mutually exclusive in cells with a normal cell cycle. Since the latter cells are consistently cell cycle arrested, the combination of antibodies detecting p16INK4a and the cell cycle progression marker Ki-67 in one cell allows for the unequivocal identification of truly HPV-transformed cervical cells $[8,9]$.

The present study was conducted to analyze Chlamydia trachomatis infection and its status with cytology, p16/
Ki-67 dual-stained cytology and CIN status in a screening cohort in Brazil.

\section{Methods}

This was a cross-sectional study of 1481 cervical samples preserved in liquid media, collected from asymptomatic women aged 18 to 64 and enrolled in a cervical cancer screening project in one clinical center (Leonor Mendes de Barros Hospital) in Sao Paulo, Brazil. Pregnant or hysterectomized women or women being treated for cervical neoplasia were excluded from the study. All women included in the study filled out a questionnaire on risk factors for cervical cancer. Cervical samples were collected at the ectocervix/endocervical junction with a Rover's Cervex-Brush and the material was placed in the liquid preservative medium (Fig. 1).

\section{Cytology slides preparation}

The entire brush head was introduced into the tube containing the BD SurePath ${ }^{\text {Tx }}$ liquid (BD Diagnostics TriPath, Burlington, NC, USA), and sent to laboratory. The slides were prepared according to the manufacturer's instructions, using $B D$ PrepMate ${ }^{\mathrm{TM}}$ and $B D$ PrepStain $^{\text {Tn }}$. All liquid-based preparations were performed with a semi-automated methodology, according to the manufacturer's instructions and manually analyzed.

Cytological changes were classified according to the 2014 Bethesda System [10] A colposcopy examination was requested for women with cytological abnormalities equal to or worse than Atypical Squamous Cells of Undetermined Significance (ASCUS).

\section{Chlamydia trachomatis detection}

One thousand four hundred eighty one samples were collected for $\mathrm{Ct}$ detection in the $\mathrm{BD}$ cytology residual

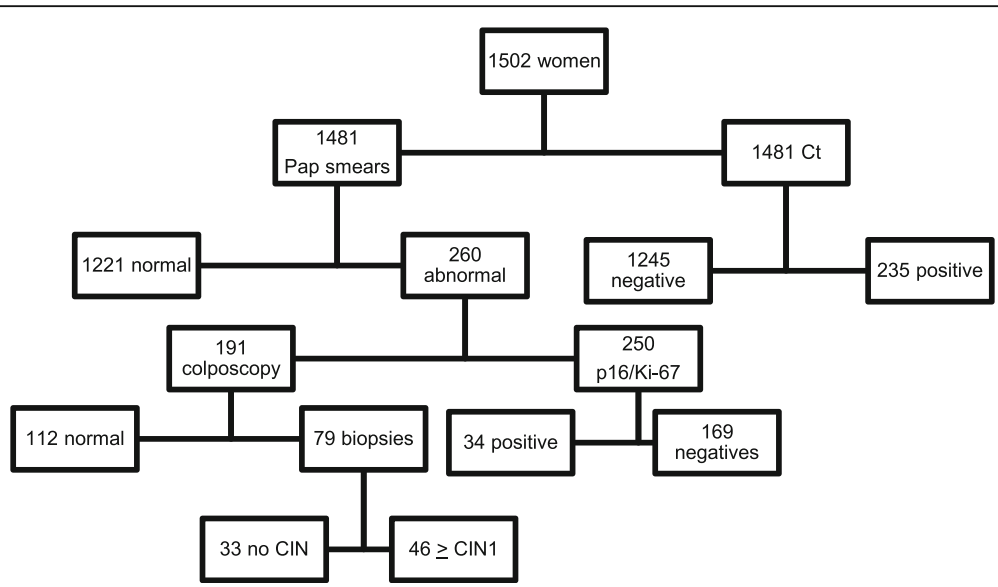

Fig. 1 Description of Biopsies According to Presence of Chlamydia trachomatis. Flowchart for the tests performed. CIN cervical intraepithelial neoplasia, Ct Chlamydia trachomatis 
medium with the BD ProbeTec Amplified DNA Test, according to the manufacturer's instructions.

\section{Immunocytochemistry of p16/Ki-67 dual-staining}

The CINtec PLUS p16/Ki-67 dual-staining analysis was conducted in cytology results equal to or worse than ASCUS.

Immunostaining was performed according to the manufacturer's instructions (Ventana, currently Roche Diagnostics GmbH, Mannheim, Germany).

The slides were analyzed searching for the presence of cervical epithelial cytoplasmic brown color and a red nuclear color, indicating concurrent expression of p16 and Ki-67. The presence of one or more cervical epithelial cells with both brown and red color was interpreted as a positive test result. The analyses were made by one of the authors (ALF).

\section{Statistics}

Sample size for this study was based on the study of Santos et al. (2002), which detected a Ct prevalence of $20.7 \%$ in women aged 14 to 63 . To obtain a similar frequency, with $95 \% \mathrm{CI}$ and $2 \%$ error, the present study would have to include 1576 women. However, due to reading failures and material losses, 1481 women were analyzed, thereby attributing an error of $2.07 \%$ to the study.

Statistical analysis was conducted based on chisquared or likelihood-ratio tests. Odds ratio (OR) and the respective $95 \%$ confidence intervals (95\% CI) were estimated.

\section{Results}

\section{Characteristics of the study population}

The ages of the women enrolled for cervical cancer screening ranged from 18 to 64 years, with a mean of 40 years $(\mathrm{SD}=11.2)$. Most women self-identified as White (58\%), 33\% were Afro-American while the remaining $9 \%$ were mixed race. The majority of subjects (57\%) had a stable partner. The mean age at first sexual intercourse was 18 years $(\mathrm{SD}=3.9)$. The number of lifetime sexual partners ranged from 1 to 30, with a mean of 3 partners $(\mathrm{SD}=2.5)$.

Among the 1,481 women, 772 reported to have had at least one prior Pap test examination. Among of the 1351 women who answered the question regarding previous sexually transmitted disease (STD), 87\% reported not to have had any prior STD. In relation to smoking, $64 \%$ of the women reported to never have smoked, and $17 \%$ of the women stopped smoking in the past 12 months.

\section{Frequency of $\mathrm{Ct}$ and association with p16/Ki-67}

The Ct frequency was of $15.9 \%$. No association was found between $\mathrm{Ct}$ and $\mathrm{p} 16 / \mathrm{Ki}-67$ positivity in women with
Table 1 Association of Chlamydia trachomatis with p16/Ki-67

\begin{tabular}{|c|c|c|c|c|c|c|c|}
\hline \multirow[t]{3}{*}{ Variable } & \multicolumn{4}{|c|}{ Chlamydia } & \multirow[t]{3}{*}{ OR $(95 \% \mathrm{Cl})$} & \multirow[t]{3}{*}{ Total } & \multirow[t]{3}{*}{$P$} \\
\hline & \multicolumn{2}{|c|}{ Negative } & \multicolumn{2}{|c|}{ Positive } & & & \\
\hline & $n$ & $\%$ & $n$ & $\%$ & & & \\
\hline \multicolumn{8}{|l|}{ p16/Ki67 } \\
\hline Negative & 140 & 84.3 & 26 & 15.7 & 1 & 166 & 0.529 \\
\hline Positive & 28 & 80.0 & 7 & 20.0 & $1.35(0.5-3.4)$ & 35 & \\
\hline
\end{tabular}

abnormal cytology (Table 1). Only age (Table 2) and the number of lifetime sexual partners (Table 3) showed an association with detection of $\mathrm{Ct}$ (Tables 1 and 2).

In particular women between 35 and 45 years old had a higher rate of $\mathrm{Ct}$ positivity when compared to women in other age groups. Women with over 10 lifetime partners had the highest rate of being positive for $\mathrm{Ct}(p$ $=0.015 \mathrm{OR}=4.14)$ (Tables 3,4 and 5).

Among the histological results, women diagnosed with CIN1 had a higher frequency of $\mathrm{Ct}$ compared to women with other cytological findings, but the difference was not statistically significant $(p=0.112)$ (Table 6).

Regarding the cytological findings, there was an association between $\mathrm{p} 16 / \mathrm{Ki}-67$ positivity and detection of high-grade lesions $(\mathrm{OR}=3.55)$, confirmed in women with CIN 2/3 who were highly positive for $\mathrm{p} 16 / \mathrm{Ki} 67$ (Tables 7 and 8).

\section{Discussion}

Prior studies have investigated the role of microorganisms like $\mathrm{Ct}$ that cause a chronic inflammation as a potential risk factor in the transmission and persistence of $\mathrm{HPV}$, as well as contributing to the progression of cervical carcinogenesis $[11,12]$. Our study population had a $15.6 \%$ frequency of $\mathrm{Ct}$ infection, as assessed by analysis of the liquid preservative media utilized for cervical cancer screening. However, we did not detect an association between p16/Ki-67 expression and $\mathrm{Ct}$ in women with CIN.

In Brazil, four studies conducted in different states, one in Goiás, two in Paraná and one in Rio Grande do Norte showed a Ct prevalence of 10.9, 10.7, 12.7 and $10.9 \%$, respectively, also compatible with results in the present study. A study conducted in the city of Manaus had a higher prevalence of $20.7 \%$, and may be explained by regional or socioeconomic reasons [4, 13-15].

$\mathrm{Ct}$ is not an infection subjected to mandatory reporting in Brazil. Additionally, there are no specific programs implemented by the Ministry of Health to encourage screening for this infection. Because it is asymptomatic in most women, it is likely to be under-diagnosed. As such, its true prevalence in this country remains ambiguous. Asymptomatic untested women are obviously not treated. This may account for the high number of positive women in our study. The $\mathrm{Ct}$ prevalence estimates must be 
Table 2 Frequency of Chlamydia trachomatis according to demographic variables

\begin{tabular}{|c|c|c|c|c|c|c|c|}
\hline \multirow[t]{3}{*}{ Variable } & \multicolumn{4}{|c|}{ Chlamydia trachomatis } & \multirow[t]{3}{*}{ OR (95\% Cl) } & \multirow[t]{3}{*}{ Total } & \multirow[t]{3}{*}{$p$} \\
\hline & \multicolumn{2}{|c|}{ Negative } & \multicolumn{2}{|c|}{ Positive } & & & \\
\hline & $n$ & $\%$ & $n$ & $\%$ & & & \\
\hline \multicolumn{8}{|l|}{ Age Group } \\
\hline$\leq 25$ & 125 & 88.7 & 16 & 11.3 & 1 & 141 & 0.040 \\
\hline $26-35$ & 295 & 84.5 & 54 & 15.5 & $1.43(0.8-2.6)$ & 349 & \\
\hline $36-45$ & 352 & 80.2 & 87 & 19.8 & $1.93(1.1-3.4)$ & 439 & \\
\hline $46-55$ & 352 & 86.3 & 56 & 13.7 & $1.24(0.7-2.2)$ & 408 & \\
\hline$>55$ & 126 & 87.5 & 18 & 12.7 & $1.12(0.5-2.3)$ & 144 & \\
\hline \multicolumn{8}{|l|}{ Schooling (Years) } \\
\hline$<8$ & 392 & 82.9 & 81 & 17.1 & 1 & 473 & 0.156 \\
\hline $8-11$ & 634 & 86.4 & 100 & 13.6 & $0.76(0.6-1.0)$ & 734 & \\
\hline$>11$ & 182 & 82.4 & 39 & 17.6 & $1.04(0.7-1.6)$ & 221 & \\
\hline \multicolumn{8}{|l|}{ Marital Status } \\
\hline Single & 530 & 85.8 & 88 & 14.2 & 1 & 618 & 0.211 \\
\hline Living with partner & 696 & 83.4 & 139 & 16.6 & $1.20(0.9-1.6)$ & 835 & \\
\hline \multicolumn{8}{|l|}{ Smoking } \\
\hline Never & 793 & 85.7 & 132 & 14.3 & 1 & 925 & 0.128 \\
\hline Currently & 234 & 81.0 & 55 & 19.0 & $1.41(1.0-2.0)$ & 289 & \\
\hline Previously & 202 & 83.1 & 41 & 16.9 & $1.22(0.8-1.8)$ & 243 & \\
\hline
\end{tabular}

Table 3 Frequency of Chlamydia trachomatis according to sexual and obstetric history

Age at sexual debut (years)

$\begin{array}{llllllll}<15 & 299 & 84.0 & 57 & 16.0 & 1 & 356 & 0.875 \\ 16-19 & 622 & 84.6 & 113 & 15.4 & 0.95(0.7-1.3) & 735 & \\ >19 & 298 & 85.4 & 51 & 14.6 & 0.90(0.6-1.3) & 349 & \end{array}$

Number of Lifetime Partners

$\begin{array}{llllllll}1-4 & 1022 & 85.3 & 176 & 14.7 & 1 & 1198 & 0.015 \\ 5-10 & 195 & 82.3 & 42 & 17.7 & 1.25(0.9-1.8) & 237 & \\ >10 & 12 & 60.0 & 8 & 40.0 & 3.87(1.56-9.61) & 20 & \end{array}$

Number of Partners in the Past Year

\begin{tabular}{clllllll}
$0-1$ & 1160 & 84.7 & 209 & 15.3 & 1 & 1369 & 0.709 \\
$2-4$ & 75 & 81.5 & 17 & 18.5 & $1.26(0.7-2.2)$ & 92 & \\
$>4$ & 5 & 83.3 & 1 & 16.7 & $1.11(0.1-9.5)$ & 6 & \\
Parity & & & & & & & \\
0 & 230 & 85.2 & 40 & 14.8 & 1 & 270 & 0.804 \\
$1-2$ & 543 & 85.0 & 96 & 15.0 & $1.02(0.7-1.5)$ & 639 & \\
$>2$ & 443 & 83.7 & 86 & 16.3 & $1.12(0.7-1.7)$ & 529 & \\
Prior STD & & & & & & & \\
No & 999 & 85.5 & 170 & 14.5 & 1 & 1169 & 0.083 \\
Yes & 130 & 80.2 & 32 & 19.8 & $1.45(0.9-2.2)$ & 162 & \\
\hline
\end{tabular}

interpreted within the context of national and cultural differences, of sexual behavior and the health system. Brazil is a very large country whose population has different cultural and socioeconomic development levels, which most likely explains the reported regional differences [16-18].

Age was the only demographic variable in this study that was associated with $\mathrm{Ct}$ infection. Women aged 35 to 45 years had the highest likelihood of being $\mathrm{Ct}$ positive. This observation differs from studies conducted in the United States, where the highest prevalence was among women aged 15 to 24 years. In the United States

Table 4 Result of the multiple logistic regression model to explain chlamydia positivity

\begin{tabular}{llll}
\hline Variable & OR & IC (95\%) & $p$ \\
\hline $\begin{array}{l}\text { Age group (years) } \\
\leq 25\end{array}$ & 1.00 & & \\
$>25 e \leq 35$ & 1.50 & $0.81-2.77$ & 0.195 \\
$>35$ e $\leq 45$ & 2.01 & $1.12-3.63$ & 0.020 \\
$>45$ e $\leq 55$ & 1.35 & $0.73-2.47$ & 0.339 \\
$>55$ & 1.26 & $0.61-2.63$ & 0.532 \\
Number of partners in life & & & \\
$1-4$ & 1.00 & & 0.332 \\
$5-10$ & 1.20 & $0.83-1.75$ & 0.002 \\
$>10$ & 4.14 & $1.66-10.36$ & \\
\hline
\end{tabular}


Table 5 Association between Pap smears and Chlamydia trachomatis infection

\begin{tabular}{|c|c|c|c|c|c|c|c|}
\hline \multirow[t]{3}{*}{ Variable } & \multicolumn{4}{|c|}{ Chlamydia trachomatis } & \multirow[t]{3}{*}{ OR $(95 \%$ Cl) } & \multirow[t]{3}{*}{ Total } & \multirow[t]{3}{*}{$P$} \\
\hline & \multicolumn{2}{|c|}{ Negative } & \multicolumn{2}{|c|}{ Positive } & & & \\
\hline & $n$ & $\%$ & $n$ & $\%$ & & & \\
\hline \multicolumn{8}{|l|}{ Cytology } \\
\hline Normal/Inflammatory & 1038 & $84.8 \%$ & 186 & 15.2 & 1 & 1224 & \multirow[t]{6}{*}{0.935} \\
\hline ASCUS & 45 & 80.4 & 11 & 19.6 & $1.36(0.7-2.7)$ & 56 & \\
\hline LSIL & 134 & 83.8 & 26 & 16.2 & $1.08(0.7-1.7)$ & 160 & \\
\hline HSIL & 23 & 82.1 & 5 & 17.9 & $1.21(0.46-3.2)$ & 28 & \\
\hline AGC & 6 & 85.7 & 1 & 14.3 & $0.93(0.1-7.8)$ & 7 & \\
\hline SCC & 1 & 100.0 & 0 & 0 & \# & & \\
\hline
\end{tabular}

screening programs for $\mathrm{Ct}$ are available for women aged 25 years or younger, and for women at risk for this infection. Increased testing and treatment may explain the overall lower prevalence, as well as the lower rate found among women aged 25 years and older in the United States as compared to Brazil [12].

When assessing other demographic factors, such as years of schooling, marital status and smoking, there was no positive association with $\mathrm{Ct}$ presence, similar to what has been reported in other national studies [13].

The analysis of sexual and obstetric history reveals that only the number of lifetime partners was associated with being positive for $\mathrm{Ct}$. Women with more than 10 partners had a four fold higher rate of positivity than did women with 1-4 partners. This is explained by the fact that $\mathrm{Ct}$ is a sexually transmitted disease, and infection is associated with high-risk sexual behavior. This association was also demonstrated in a prior Brazilian study [13].

Because it is an infection in which $90 \%$ of infected women are asymptomatic but, nevertheless, can have serious consequences for both reproductive and fetal health, $\mathrm{Ct}$ has been considered the non-viral STD with the highest burden for public health. Several lines of evidence suggest that screening for $\mathrm{Ct}$ is cost effective when its prevalence is above $3 \%$. The few Brazilian studies

Table 6 Association between biopsies and Chlamydia trachomatis infection

\begin{tabular}{|c|c|c|c|c|c|c|c|}
\hline \multirow[t]{3}{*}{ Variable } & \multicolumn{4}{|c|}{ Chlamydia trachomatis } & \multirow[t]{3}{*}{ OR $(95 \% \mathrm{Cl})$} & \multirow[t]{3}{*}{ Total } & \multirow[t]{3}{*}{$P$} \\
\hline & \multicolumn{2}{|c|}{ Negative } & \multicolumn{2}{|c|}{ Positive } & & & \\
\hline & $n$ & $\%$ & $n$ & $\%$ & & & \\
\hline \multicolumn{8}{|l|}{ Histology } \\
\hline Normal & 86 & $79.6 \%$ & 22 & 20.4 & 1 & 108 & 0.194 \\
\hline Cervicitis & 30 & 93.8 & 2 & 6.2 & $0.26(0.06-1.18)$ & 32 & \\
\hline CIN 1 & 21 & 77.8 & 6 & 22.2 & $1.12(0.40-3.1)$ & 27 & \\
\hline $\mathrm{CIN} 2 / 3$ & 10 & 76.9 & 3 & 23.1 & $1.17(0.3-4.63)$ & 13 & \\
\hline
\end{tabular}

CIN 1 cervical intraepithelial neoplasia 1

CIN2/3 cervical intraepithelial neoplasia 2 and 3 conducted until now clearly justify the implementation of systematic screening of women for this infection [18].

We did not observe an association between abnormal cervical cytology and the presence of Ct. An analysis of women with abnormal cytological results revealed a higher prevalence of $\mathrm{Ct}$ infection in women with atypical lesions (ASCUS), followed by low-grade lesions (LSIL), in which almost $20 \%$ were $\mathrm{Ct}$ positive. These observed rates were similar to other Brazilian studies with women in the same age group [14].

In women who underwent a colposcopy examination a greater prevalence of $\mathrm{Ct}$ positivity was found in women with CIN1. However, the lack of statistical significance may be due to the low number of biopsies conducted after the cytology results. No prior Brazilian studies have assessed this association.

Our study was limited by the lack of HPV testing, due to the limited amount of residual material available. It is necessary, however, to take into consideration the "status" of HPV infection and the natural history of cervical cancer when determining the role of $\mathrm{Ct}$ as a co-factor in CIN or invasive cancer. HPV infection is a highly prevalent sexually transmitted viral infection, whereas $\mathrm{Ct}$ is the most commonly sexually transmitted bacterial infection, and co-infections with both microorganisms are quite common. No association was found in this study between $\mathrm{Ct}$ infection and cytology and positive biopsies for CIN, presumed positive for HPV. These results differ from other studies that found a positive association between HPV and Ct detected by serology [19, 20],

Table 7 Association of p16/Ki-67 expression with Low-grade and High-Grade Cytological Diagnosis

\begin{tabular}{|c|c|c|c|c|c|c|c|}
\hline \multirow[t]{3}{*}{ Variable } & \multicolumn{4}{|c|}{ Cytology } & \multirow[t]{3}{*}{ OR $(95 \% \mathrm{Cl})$} & \multirow[t]{3}{*}{ Total } & \multirow[t]{3}{*}{$P$} \\
\hline & \multicolumn{2}{|c|}{$\overline{\text { ASCUS/LSIL }}$} & \multicolumn{2}{|c|}{$\mathrm{HSIL}$} & & & \\
\hline & $\bar{n}$ & $\%$ & $\bar{n}$ & $\%$ & & & \\
\hline \multicolumn{8}{|l|}{ P16/ki67 } \\
\hline Negative & 141 & 88.1 & 19 & 11.9 & 1.00 & 160 & 0.003 \\
\hline Positive & 23 & 67.6 & 11 & 32.4 & $3.55(1.50-8.42)$ & 34 & \\
\hline
\end{tabular}


Table 8 Association of p16/Ki67 Expression with colposcopy and histological results

\begin{tabular}{|c|c|c|c|c|c|c|c|}
\hline \multirow[t]{3}{*}{ Variable } & \multicolumn{4}{|c|}{ P16/Ki67 } & \multirow[t]{3}{*}{ OR $(95 \% \mathrm{Cl})$} & \multirow[t]{3}{*}{ Total } & \multirow[t]{3}{*}{$P$} \\
\hline & \multicolumn{2}{|c|}{ Negative } & \multicolumn{2}{|c|}{ Positive } & & & \\
\hline & $n$ & $\%$ & $n$ & $\%$ & & & \\
\hline \multicolumn{8}{|l|}{ Colposcopy/Biopsies } \\
\hline Normal Colposcopy/No Biopsy & 76 & 90.5 & 8 & 9.5 & 1.00 & 84 & \multirow[t]{5}{*}{$<0.001$} \\
\hline Cervicitis & 22 & 81.5 & 5 & 18.5 & $2.16(0.64-7.27)$ & 27 & \\
\hline CIN 1 & 20 & 76.9 & 6 & 23.1 & $2.85(0.89-9.16)$ & 26 & \\
\hline CIN 2/3 & 4 & 33.3 & 8 & 66.7 & $19.00(4.67-77.36)$ & 12 & \\
\hline Total & 122 & 81.9 & 27 & 18.1 & & 149 & \\
\hline
\end{tabular}

Chi-squared test; OR and IC (95\%) calculated using bivariate logistic regression

CIN1 cervical intraepithelial neoplasia 1

CIN2/3 cervical intraepithelial neoplasia 2 and 3

However it was similar to other studies using the same methodology that did not find any association between $C t$ DNA detection and subsequent risk of CIN2/3 [21, 22].

This study utilized p16/Ki-67 expression as a marker of transforming HPV infections. The study was designed to explore the possible association between a $C t$ infection and consequences of a persistent HPV infection by the use of p16/Ki-67, instead of testing for HPV DNA. In most cases, HPV DNA is unable to distinguish between persistent and transient infection. We conclude that there is no association between $\mathrm{Ct}$ and $\mathrm{p} 16 / \mathrm{Ki}-67$ positivity in women with abnormal cytology [22].

Most women with cytological findings were negative for p16/Ki-67 expression. However, approximately one fourth of the abnormal cytological results were positive for p16/Ki-67 double staining, a finding compatible with publications demonstrating that women with p16/Ki-67 positivity were also the women infected with HPV. Women with HSIL had a higher positivity prevalence (37\%) than did women with LSIL. p16/Ki-67 positivity is therefore associated with a threefold higher prevalence in women with a high-grade lesion. These results were comparable to a recent study assessing the use of p16/ $\mathrm{Ki}-67$ in a sample from women referred for colposcopy and finding that this marker indeed had a higher positivity in women with high-grade lesions [23, 24].

Evaluation of the association of p16/Ki-67 expression with histopathological results also revealed a higher rate of $\mathrm{p} 16 / \mathrm{Ki}-67$ positivity in women with CIN2 or more advanced lesions. p16/Ki-67 positivity increased with the seriousness of the lesion. When the biopsy result revealed chronic cervicitis, approximately $20 \%$ of the cases were positive; positivity was higher with CIN1 (25\%) and, in women with CIN2 or more advanced lesions, almost $70 \%$ of the cytological preparations were positive for the double stain. The results are consistent with other studies in which p16/
Ki-67 activity in a colposcopy population had similar associations [24].

A possible relationship between $\mathrm{Ct}$ and either cytological or histopathological alterations characteristic of HPV infection remains to be clarified. An association between $\mathrm{Ct}$ and a persistent HPV infection may occur preferentially in high-risk women, while a Ct infection may be associated with the clearance of an HPV infection in women who develop an intense inflammatory response to $\mathrm{Ct}$. The identification of women in whom a concurrent $\mathrm{Ct}$ infection may be beneficial or detrimental to HPV persistence and progression remains to be clarified $[21,25,26]$.

\section{Conclusion}

$\mathrm{Ct}$ infection in our study population had a frequency of $15.6 \%$ and was associated with age and number of lifetime sexual partners. It was not associated with p16/Ki-67 expression in women with CIN. A possible relationship between $\mathrm{Ct}$ and either cytological or histopathological alterations leading to development or persistence of HPV infection remains to be clarified.

\section{Abbreviations \\ AGC: Atypical glandular cells; ASCUS: Atypical squamous cells of undetermined significance; CIN: Cervical intraepithelial lesions; CIN 1: Cervical intraepithelia neoplasia 1; CIN2/3: Cervical intraepithelial neoplasia 2 and 3; Ct: Chlamydia trachomatis; HPV: Human papillomavirus; HSIL: High-grade squamous intraepithelial lesions; LSIL: Low-grade lesions; SCC: Squamous cell carcinoma}

\section{Acknowledgements}

The authors thank the study participants, and of Hospital Leonor Mendes de Barros local team.

\section{Funding}

The authors received no financial support or other form of compensation for the development of the manuscript.

\section{Availability of data and materials}

The datasets generated during and/or analyzed during the current study are available from the corresponding author on reasonable request. 


\section{Authors' contributions}

All authors contributed towards study conception/design of this study. RR and RMCC participated in the recruitment and/or follow-up of subjects. SFM and SD performed Ct detection. LFA and RGG performed cytology and p16/ ki-67 dual-stained. All authors read and approved the final manuscript.

\section{Competing interests}

The authors declare that they have no competing interests.

\section{Consent for publication}

Not applicable.

\section{Ethics approval}

The Committee of Ethics and Research of Hospital Leonor Mendes de Barros and Committee of Ethics of Faculdade de Medicina da Universidade de São Paulo approved this project. All women signed the Free and Clarified Consent Term (FCCT). Plataforma Brasil: (CAAE: 06562112.6.0000.0065) (CAAE: 05330412.1.0000.0063)

\section{Author details}

${ }^{1}$ Division of Gynecologic Clinic, Faculdade de Medicina da Universidade de São Paulo, São Paulo, Brazil. ' Laboratory of Medical Investigation (LIM) 14, Faculty of Medicine, University of São Paulo, São Paulo, Brazil. ${ }^{3}$ Molecular Oncology Research Center, Barretos Cancer Hospital, Pio XII Foundation, Barretos, Brazil. ${ }^{4}$ Life and Health Sciences Research Institute (ICVS), School of Health Sciences, University of Minho, Braga, Portugal. ${ }^{5}$ ICVS/3B's - PT Government Associate Laboratory, Braga/Guimarães, Portugal. ' ${ }^{2}$ eonor M De Barros Hospital - Secretaria de Saúde de São Paulo, São Paulo, Brazil. ${ }^{7}$ Federal University of Pelotas - Pelotas, Rio Grande do Sul, Brazil. ${ }^{8}$ School of Pharmaceutical Sciences of Ribeirão Preto University of São Paulo, Ribeirão Preto, Brazil. ${ }^{9}$ Discipline of Infectology, Federal University of São Paulo, São Paulo, Brazil

Received: 14 August 2016 Accepted: 13 December 2016 Published online: 06 January 2017

\section{References}

1. Motta $D$, Silva AD, Macedo ABRB, et al. Vigilância epidemiológica dos agravos de notificação compulsória. Brasília: SES/DF; 2003.

2. Fernandes LB, Arruda JT, Approbato MS, et al. Chlamydia trachomatis and Neisseria gonorrhea infection: factors associated with infertility in women treated at a human reproduction public service. Rev Bras Ginecol Obstet. 2014;36(8):353-8.

3. Pantoja M, Campos EA, Pitta DR, et al. Prevalence of Chlamydia trachomatis infection among women candidates for in vitro fertilization at a public institution of the State of Sao Paulo, Brazil. Rev Bras Ginecol Obstet. 2012; 34(9):425-31.

4. Piazzetta RC, de Carvalho NS, de Andrade RP, et al. Prevalence of Chlamydia trachomatis and Neisseria gonorrhea infections in sexual actives young women at a southern Brazilian city. Rev Bras Ginecol Obstet. 2011;33(11): 328-33.

5. Silva J, Cerqueira F, Medeiros R. Chlamydia trachomatis infection: implications for HPV status and cervical cancer. Arch Gynecol Obstet. 2014; 289(4):715-23.

6. Nanda K, McCrory DC, Myers ER, et al. Accuracy of the Papanicolaou test in screening for and follow-up of cervical cytological abnormalities: a systematic review. Ann Intern Med. 2000;132(10):810-9.

7. Ordi J, Sagasta A, Munmany M, et al. Usefulness of p16/Ki67 immunostaining in the triage of women referred to colposcopy. Cancer Cytopathol. 2014;122(3):227-35.

8. Bergeron $\mathrm{C}$, Ronco $\mathrm{G}$, Reuschenbach $\mathrm{M}$, et al. The clinical impact of using p16 immunochemistry in cervical histopathology and cytology: an update of recent developments. Int J Cancer. 2015;136(12):2741-51.

9. Bergeron C, von Knebel Doeberitz M. The role of cytology in the 21st century: The integration of cells and molecules. Acta Cytol. 2016;60:540-542.

10. Nayar R, Wilbur DC. The Bethesda system for reporting cervical cytology. definitions, criteria, and explanatory notes. 3rd ed. Springer; 2015.

11. Luostarinen T, Namujju PB, Merikukka M, et al. Order of HPV/Chlamydia infections and cervical high-grade precancer risk: a case-cohort study. Int J Cancer. 2013;133(7):1756-9.
12. Shew ML, Ermel AC, Weaver BA, et al. Association of Chlamydia trachomatis infection with redetection of human papillomavirus after apparent clearance. J Infect Dis. 2013;208(9):1416-21.

13. de Abreu AL, Nogara PR, Souza RP, et al. Molecular detection of HPV and Chlamydia trachomatis infections in Brazilian women with abnormal cervical cytology. Am J Trop Med Hyg. 2012;87(6):1149-51.

14. Magalhaes PA, Miranda CA, Lima EG, et al. Genital tract infection with Chlamydia trachomatis in women attended at a cervical cancer screening program in Northeastern from Brazil. Arch Gynecol Obstet. 2015;291(5): 1095-102.

15. Santos C, Teixeira F, Vicente A, et al. Detection of Chlamydia trachomatis in endocervical smears of sexually active women in Manaus-AM, Brazil, by PCR. Braz J Infect Dis. 2003;7(2):91-5.

16. Brasil. Ministério da Saúde. Available: http://bvsms.saude.gov.br/bvs/ saudelegis/gm/2016/prt0204_17_02_2016.html

17. Redmond SM, Alexander-Kisslig K, Woodhall SC, et al. Genital chlamydia prevalence in Europe and non-European high income countries: systematic review and meta-analysis. PLoS One. 2015;10(1):e0115753.

18. Low N, Cassell JA, Spencer B, et al. Chlamydia control activities in Europe: cross-sectional survey. Eur J Public Health. 2012;22(4):556-61.

19. Owusu-Edusei Jr K, Chesson HW, Gift TL, et al. The estimated direct medical cost of selected sexually transmitted infections in the United States, 2008. Sex Transm Dis. 2013;40(3):197-201

20. Safaeian M, Quint K, Schiffman M, et al. Chlamydia trachomatis and risk of prevalent and incident cervical premalignancy in a population-based cohort. J Nat Cancer Inst. 2010;102(23):1794-804.

21. Smith JS, Bosetti C, Munoz N, et al. Chlamydia trachomatis and invasive cervical cancer: a pooled analysis of the IARC multicentric case-control study. Int J Cancer. 2004;111(3):431-9.

22. Moscicki $A B$, Schiffman $M$, Burchell $A$, et al. Updating the natural history of human papillomavirus and anogenital cancers. Vaccine. 2012;30 Suppl 5 F24-33.

23. Jensen KE, Thomsen LT, Schmiedel S, Frederiksen K, Norrild B, van den Brule A, Iftner T, Kjær SK. Chlamydia trachomatis and risk of cervical intraepithelial neoplasia grade 3 or worse in women with persistent human papillomavirus infection: a cohort study. Sex Transm Infect. 2014;90(7):550-5.

24. Longatto Filho A, Utagawa ML, Shirata NK, et al. Immunocytochemical expression of p16INK4A and Ki-67 in cytologically negative and equivocal pap smears positive for oncogenic human papillomavirus. Int J Gynecol Pathol. 2005;24(2):118-24.

25. Wentzensen N, Schwartz L, Zuna RE, et al. Performance of p16/Ki-67 immunostaining to detect cervical cancer precursors in a colposcopy referral population. Clin Cancer Res. 2012;18(15):4154-62.

26. Rosa MI, Fachel JM, Rosa DD, et al. Persistence and clearance of human papillomavirus infection: a prospective cohort study. Am J Obstet Gynecol. 2008;199(6):617 e1-7.

\section{Submit your next manuscript to BioMed Central and we will help you at every step:}

- We accept pre-submission inquiries

- Our selector tool helps you to find the most relevant journal

- We provide round the clock customer support

- Convenient online submission

- Thorough peer review

- Inclusion in PubMed and all major indexing services

- Maximum visibility for your research

Submit your manuscript at www.biomedcentral.com/submit
) Biomed Central 